\title{
Induced sputum IL-8 gene expression, neutrophil influx and MMP-9 in allergic bronchopulmonary aspergillosis
}

\author{
P.G. Gibson*, P.A.B. Wark", J.L. Simpson*, C. Meldrum ${ }^{\top}$, S. Meldrum ${ }^{+}$, N. Saltos*, M. Boyle
}

Induced sputum IL-8 gene expression, neutrophil influx and MMP-9 in allergic bronchopulmonary aspergillosis. P.G. Gibson, P.A.B. Wark, J.L. Simpson, C. Meldrum, S. Meldrum, N. Saltos, M. Boyle. (C) ERS Journals Ltd 2003.

ABSTRACT: Allergic bronchopulmonary aspergillosis (ABPA) is a hypersensitivity reaction to the fungus Aspergillus fumigatus, causing severe asthma that may progress to bronchiectasis. Sputum neutrophilia can occur in association with sputum eosinophilia and correlates with the degree of bronchiectasis. The mechanisms of sputum neutrophilia in ABPA are not known. The aim of this study was to investigate the role of the chemokine interleukin (IL)-8 in sputum neutrophilia in ABPA.

Induced sputum was obtained from subjects with ABPA $(n=29)$, and compared to nonsensitised asthma $(n=9)$ and healthy controls $(n=21)$. Semiquantitative polymerase chain reaction was used to assess IL-8 gene expression in induced sputum and IL-8 protein was measured by enzyme-linked immunosorbent assay.

Sputum IL-8 protein was significantly higher in ABPA compared to asthma and controls. IL-8 messenger ribonucleic acid/glyceraldehyde-3-phosphate dehydrogenase ratio was elevated in ABPA compared to asthma and controls. Sputum IL-8 correlated with sputum neutrophils, matrix metalloproteinase-9 levels and forced expiratory volume in one second.

Interleukin-8 gene expression and protein release were increased in allergic bronchopulmonary aspergillosis and correlated with airway neutrophilia and airway obstruction. The interleukin-8-mediated neutrophil influx in allergic bronchopulmonary aspergillosis may induce lung damage via release of matrix metalloproteinase-9, potentially leading to bronchiectasis.

Eur Respir J 2003; 21: 582-588.
*Depts of Respiratory and Sleep Medicine, "Cell and Molecular Biology and ${ }^{+}$Immunology and Infectious Diseases, John Hunter Hospital and School of Medical Practice and Population Health, Faculty of Health, University of Newcastle, Newcastle, Australia. ${ }^{\#}$ Respiratory Cell and Molecular Biology, Research Division, Southampton General Hospital, Southampton, UK.

Correspondence: P.G. Gibson, Dept of Respiratory and Sleep Medicine, John Hunter Hospital, Locked Bag 1, Hunter Region Mail Centre, NSW 2310, Australia.

Fax: 61249213469

E-mail:mdpgg@mail.newcastle.edu.au

Keywords: Allergic aspergillosis, asthma, induced sputum, interleukin-8

Received: January 142002

Accepted after revision: December 32002

This study was supported by the Asthma Foundation of New South Wales and the National Health and Medical Research Council of Australia.
Chronic airway inflammation and airway remodelling underlie the disordered airway function found in asthma and allergic bronchopulmonary aspergillosis (ABPA) [1-3]. Airway colonisation and hypersensitivity to the ubiquitous fungus Aspergillus fumigatus (A. fumigatus) results in severe and chronic asthma, intermittent eosinophilic pulmonary infiltrates, and may lead to the development of bronchiectasis and fibrotic lung disease. ABPA is typically characterised by sputum eosinophilia, however, lung tissue also shows a mixed inflammatory infiltrate with eosinophils and neutrophils [4]. Recently the current authors reported that sputum neutrophils were increased in ABPA and correlated with the severity of bronchiectasis [5].

The cytokines mediating this neutrophilic response in ABPA have not been elucidated. The C-X-C chemokine interleukin (IL)- 8 is a potential candidate since it is an important neutrophil chemoattractant in the lung [6] and sputum IL-8 levels are elevated in neutrophilic airways diseases such as cystic fibrosis [7], chronic obstructive pulmonary disease (COPD) [8] and acute severe asthma [9]. In addition, IL-8 causes secretion of a number of enzymes capable of tissue destruction, such as elastase and matrix metalloproteinase (MMP)-9 [10, 11]. Therefore, IL-8 may be a key mediator of chronic airway damage and remodelling in ABPA. In this study the authors investigated whether induced sputum IL-8 gene expression and protein secretion were elevated in ABPA, and correlated with the extent of the neutrophil influx and MMP-9 release in ABPA.

\section{Methods}

Design

Subjects with ABPA attended for two visits. At the first visit, a clinical history was obtained followed by venepuncture for immune markers, spirometry, hypertonic saline challenge, sputum induction and then allergy skin-prick tests (SPT). A high-resolution computed tomography (HRCT) scan of the thorax was performed within 14 days of the clinical assessment. Subjects with asthma and controls attended a single visit for clinical assessment, spirometry, saline challenge, sputum induction and allergy SPT. The Hunter Area Health Research Ethics Committee approved the study and all subjects gave written informed consent.

\section{Subjects}

A total of 59 nonsmoking subjects were studied. Adults with stable asthma were recruited from the respiratory clinic of the John Hunter Hospital and classified as ABPA ( $n=29)$ or non- $A$. fumigatus-sensitised asthma $(\mathrm{n}=9)$, as previously described [5]. Twenty-one healthy controls were recruited by advertisement. Subjects were excluded if they reported an exacerbation of asthma or respiratory tract infection within the past 6 weeks. Subjects with cystic fibrosis were excluded, 
and if there was a clinical suspicion of this, sweat electrolyte testing was performed.

Asthma was diagnosed using American Thoracic Society criteria and based upon a compatible history together with either airway hyperresponsiveness (provocative dose of saline causing a $20 \%$ fall in forced expiratory volume in one second (FEV1) $<15 \mathrm{~mL}$ ), or an improvement in FEV1 of $>15 \%$ after albuterol $200 \mu \mathrm{g}$. Stability of asthma was defined as no deterioration in symptoms or peak flow or increased use of bronchodilator medication in the preceding 6 weeks. Sensitisation to $A$. fumigatus was determined by an immediate reaction to SPT (weal $>3 \mathrm{~mm}$ ), carried out using a 1:10 weight:volume dilution of A. fumigatus (Bayer Australia Ltd, Pymble, Australia).

\section{Subject classification}

Subjects with ABPA were classified using published diagnostic criteria [3]. All cases were reviewed by three respiratory physicians and were included only if a consensus was reached. Those with ABPA were required to have the following as minimum criteria: asthma, evidence of immunoglobulin (Ig)E sensitisation to A. fumigatus with a positive SPT, a total serum $\mathrm{IgE}$ of $>1,000 \mathrm{IU} \cdot \mathrm{mL}^{-1}$, elevated $\mathrm{IgE}$ and $\mathrm{IgG}$ antibodies to A. fumigatus. Evidence of central bronchiectasis on HRCT was also used as a major criterion for the diagnosis of ABPA. Those with asthma alone had no evidence of sensitisation to A. fumigatus. Healthy controls had neither asthma nor sensitisation to A. fumigatus.

\section{Immunological parameters}

Full blood count and differential were performed using a Coulter Gen-S (Beckman-Coulter, Australia Pty Ltd, Sydney, Australia). Measurement of total serum IgE was carried out using a Unicap system (Pharmacia-Upjohn Diagnostics, AB, Uppsala, Sweden). The presence of specific precipitating IgG antibodies to $A$. fumigatus was detected using a serological double- gel diffusion assay. Serum IgE antibodies to $A$. fumigatus were measured using a Pharmacia CAP immunoassay (Kabi Pharmacia Diagnostics, AB, Uppsala, Sweden). Serum IgG antibodies to $A$. fumigatus (IgG $A f$ ) were assessed by enzyme-linked immunosorbent assay (ELISA) with purified Aspergillus antigen (Genesis Diagnostics, Cambridgeshire, UK).

\section{Pulmonary function tests}

All patients underwent spirometry (Minato Autospiro AS600; Minato Medical Science Co Ltd, Osaka, Japan) and bronchial provocation testing with hypertonic $(4.5 \%)$ saline, as described previously [12], using a DeVilbiss 2000 ultrasonic nebuliser (Oregon, Pike, PA, USA) and a Hans Rudolph 2700 two-way nonrebreathing valve box (Hans Rudolph Inc., KS, USA) with a rubber mouthpiece and noseclips. The nebuliser output was $1.8 \mathrm{~mL} \cdot \mathrm{min}^{-1}$ and particle size (mass median aerodynamic diameter) $<5 \mu \mathrm{m}$.

\section{Sputum induction}

Sputum was induced during the hypertonic saline challenge as described previously [13]. Subjects were asked to rinse their mouth with water before the procedure to help minimise squamous cell contamination. They were asked to cough between each dose of nebulised saline to clear their throat and expectorate into the container.

\section{Sputum analysis}

Lower respiratory sputum portions were selected from saliva and processed as described previously [13]. Briefly, selected sputum was dispersed by adding four volumes of $0.1 \%$ dithiothreitol (DTT-Sputolysin 10\%; Calbiochem Corp., La Jolla, CA, USA), mixed in a shaking waterbath at $37^{\circ} \mathrm{C}$ for $30 \mathrm{~min}$, filtered through $60 \mu \mathrm{m}$ nylon gauze (Millipore North Ryde, NSW, Australia) and a total cell count of nonsquamous cells and viability was determined from the filtrate. Supernatant was aspirated and stored at $-70^{\circ} \mathrm{C}$ and cytospins prepared form the resuspended cell pellet (Shandon Cytospin, Sewickey, PA, USA).

A differential count was obtained from 400 cells counted on May-Grunwald-Giemsa-stained cytoprep. Eosinophils were enumerated from slides stained with Chromotrope $2 \mathrm{R}$ in the same fashion. Cells staining positive for IL-8 were identified using a monoclonal antibody (mouse anti-human IL-8; Pharmingen, San Diego, CA, USA) and detected using the alkaline phosphatase anti-alkaline phosphatase technique, as described previously [9, 13]. The concentrations of IL-8, MMP-9 and eosinophil cationic protein (ECP) were determined in thawed sputum supernatants. ECP was determined by radioimmunoassay (Kabi Pharmacia Diagnostics AB). MMP-9 and IL-8 were determined by ELISA (R\&D systems, Minneapolis, MN, USA) with standard curves based on dilutions of purified ECP, MMP-9 and recombinant IL-8. The lower limits of detection of the fluid phase assays were ECP $2 \mu \mathrm{g} \cdot \mathrm{mL}^{-1}$, MMP-9 $1.6 \mathrm{ng} \cdot \mathrm{mL}^{-1}$ and IL-8 $32 \mathrm{pg} \cdot \mathrm{mL}^{-1}$.

\section{Interleukin-8 gene expression}

Ribonucleic acid extraction from sputum samples. Ribonucleic acid (RNA) was extracted from sputum samples using a two-stage Trizol reagent (Gibco BRL, Life Technologies, NY, USA) extraction method. Trizol $(500 \mu \mathrm{L})$ was added to $100 \mu \mathrm{L}$ of sputum and mixed, followed by mixing and incubation with $200 \mu \mathrm{L}$ of chloroform. The sample was then centrifuged $(12,000 \times g)$ for $15 \mathrm{~min}$ at $4^{\circ} \mathrm{C}$ and the aqueous phase was precipitated at $-70^{\circ} \mathrm{C}$ for $2 \mathrm{~h}$ with $0.5 \mathrm{~mL}$ of ice-cold isopropanol and $2 \mu \mathrm{L}$ of glycogen (Gibco BRL). The sample was centrifuged and $500 \mu \mathrm{L}$ of trizol was added to the pellet. The method was the same for the second extraction except that samples were precipitated at $-20^{\circ} \mathrm{C}$ overnight. Following centrifugation, $0.5 \mathrm{~mL}$ of ice-cold $75 \%$ ethanol was added to the pellet and recentrifuged for $5 \mathrm{~min}$ at $4{ }^{\circ} \mathrm{C}$. The ethanol was then removed and the RNA pellet dried before addition of $10 \mu \mathrm{L}$ of diethyl pyrocarbonate (DEPC)-treated water. All RNA samples were stored at $-70^{\circ} \mathrm{C}$.

The RNA yield was determined by spectrophotometry and ranged $0.03-2.03 \mu \mathrm{g} \cdot \mu \mathrm{L}^{-1}$. The RNA was reverse transcribed at a concentration of $12.5 \mathrm{ng} \cdot \mu \mathrm{L}^{-1}$ in $1 \times$ reverse transcription (RT)-buffer, $0.5 \mathrm{mM}$ deoxynucleotide triphosphates, $10 \mathrm{mM}$ DTT, 40 U RNase inhibitor (RNasin), 200 U M-MLV-reverse transcriptase and random hexamers. The reaction took place at $37^{\circ} \mathrm{C}$ for $1.5 \mathrm{~h}$ and was stopped by heating the samples at $95^{\circ} \mathrm{C}$ for $3 \mathrm{~min}$. The complementary deoxyribonucleic acid (cDNA) was stored at $4^{\circ} \mathrm{C}$.

Reverse transcription. A spectrophotometer (Cary 50 Bio; Varian, Melbourne, Australia) was used to measure the RNA yield from each sample (260:280 nm ratio). RNA was reverse transcribed at a concentration of $1.0 \mu \mathrm{g}$ per $80 \mu \mathrm{L}$ reaction 
volume. The RT reaction solution contained $16 \mu \mathrm{L}$ of $5 \times \mathrm{RT}$ buffer, $4 \mu \mathrm{L}$ of a $10 \mathrm{mM}$ dNTP mix $(0.5 \mathrm{mM}$ each of the deoxyadenosine triphosphate (dATP), deoxyguanine triphosphate (dGTP), deoxythymidine triphosphate (dTTP) and deoxycytosine triphosphate (dCTP)), $8 \mu \mathrm{L}$ of $100 \mathrm{mM}$ dithiothreitol, $2 \mu \mathrm{L}$ of $40 \mathrm{U} \cdot \mu \mathrm{L}$ RNasin, $1 \mu \mathrm{L}$ random hexamers (Boehringer Mannheim, Mannheim, Germany) and $2 \mu \mathrm{L}$ of $200 \mathrm{U} \cdot \mu \mathrm{L}^{-1} \mathrm{M}-\mathrm{MLV}$ reverse transcriptase (all RT reagents, except the random hexamers, from Promega Corporation, WI, USA) and made to $80 \mu \mathrm{L}$ with DEPC-treated water. The samples were incubated at $37^{\circ} \mathrm{C}$ for $1.5 \mathrm{~h}$ and the reaction was stopped by heating at $95^{\circ} \mathrm{C}$ for $5 \mathrm{~min}$. All cDNA samples were stored at $4{ }^{\circ} \mathrm{C}$ until used for competitive polymerase chain reaction $(\mathrm{PCR})$.

Quantitative polymerase chain reaction. Quantification of the housekeeping gene glyceraldehyde-3-phosphate dehydrogenase (GAPDH) and the cytokine IL-8 was achieved by competitive PCR [14] using a PCR MIMIC construction kit (Clontech, Palo Alto, CA, USA). This involved the construction of a nonhomologous (neutral) internal standard (MIMIC). The MIMIC is engineered to compete with the target for the specific primers in the PCR while producing a fragment of differing size.

Preparation of the MIMIC. The MIMICs were prepared according to manufacturer's instructions. Briefly, the MIMIC's were produced using two sets of primers (a composite set and a specific set) in two rounds of PCR amplification of neutral DNA. The first round of PCR involved neutral DNA and a set of composite primers. The composite primers contain the sequence for the specific primers on their $5^{\prime}$ ends and a stretch of 20 nucleotides at the $3^{\prime}$ ends that are designed to hybridise to opposite strands of the neutral DNA. The stretch of 20 nucleotides is selected so that the fragment produced upon amplification is a different size to the target fragment. Therefore, after the first round the MIMIC contains the sequence for the specific primers on its $5^{\prime}$ ends. The composite primers were as follows. GAPDH: 5'TGGCATGGACTGTGGTCATGATTTGATTCTGGACCATGGC3' and 5'CATGGAGAAGGCTGGGGCTCTGTTATACAGGGAGATGAAA3'; and IL-8: 5'AAGTTTTTGAAGAGGGCTGATACAGGGAGATGAAA3' and 5'GGATATTTCATGGTACAATGATTTGATTCTGGACCATGGC3'. A dilution of the first round of PCR was used in the second round with the specific set of primers.

The specific set of primers were as follows. GAPDH: 5'TGGCATGGACTGTGGTCATG3' and 5'CATGGAGAAGGCTGGGGCTC3'; and IL-8 were 5'AAGTTTTTGAAGAGGGCTG3' and 5'GGATATTTCATGGTACAATG3' (all primers from Gibco BRL). This round ensured that the MIMIC contained the complete target-specific primer sequences. The MIMIC was then cleaned using the Geneclean II Kit (Bio 101 Inc., Vista, CA, USA) using the manufacturer's instructions. Briefly, the second round PCR of the MIMIC was electrophoresed, the band cut from the gel, weighed and agarose removed by heating at $50^{\circ} \mathrm{C}$ with three volumes of sodium iodide (Geneclean II Kit). Glassmilk (Geneclean II Kit) was added to bind the MIMIC and the solution was centrifuged at full speed for $5 \mathrm{~s}$. The washed pellet was resuspended and centrifuged for $5 \mathrm{~s}$, three times with NEW WASH solution (Geneclean II Kit). The MIMIC was then released from the glassmilk by the addition of $10 \mu \mathrm{L}$ of DEPC-treated water and incubating at $50^{\circ} \mathrm{C}$ for $3 \mathrm{~min}$ followed by centrifuging for $30 \mathrm{~s}$ at full speed. The yield of MIMIC was calculated by comparison of the fragments in several dilutions of $\phi X 174 /$ HaeIII-digest DNA (supplied in the Clontech Kit) on an ethidium bromide-stained agarose gel according to kit instructions. The MIMIC was diluted to a $100 \mathrm{amol} \cdot \mu \mathrm{L}^{-1}$, designated M0, and a 10 -fold dilution series made from this start point. All stock solutions were stored at $-20^{\circ} \mathrm{C}$ until use to guarantee their stability.

Quantitative reaction. A PCR series containing $2 \mu \mathrm{L}$ of cDNA was spiked with $2 \mu \mathrm{L}$ of the dilution series of MIMIC. The PCR solution contained DEPC-treated water, $5 \mu \mathrm{L}$ of $10 \times$ PCR buffer (Promega Corporation), $0.5 \mathrm{mM} \mathrm{MgCl}_{2}$ (Sigma, St Louis, MO, USA), $0.2 \mathrm{mM}$ each dATP, dCTP, dGTP and dTTP (Promega Corporation, Madison, Wisconsin), $0.4 \mu \mathrm{M}$ specific primers and two units of Taq polymerase (Promega Corporation). The PCR reaction proceeded at $95^{\circ} \mathrm{C}$ for $2 \mathrm{~min}$, then 40 cycles of $95^{\circ} \mathrm{C}$ for $45 \mathrm{~s}$, annealing for $45 \mathrm{~s}$ and $72^{\circ} \mathrm{C}$ for $1.5 \mathrm{~min}$, and a final extension at $72^{\circ} \mathrm{C}$ for $10 \mathrm{~min}$. The annealing temperatures for GAPDH and IL- 8 were $63^{\circ} \mathrm{C}$ and $54^{\circ} \mathrm{C}$, respectively. During amplification the MIMIC and target competed for the specific PCR primers. When the target and MIMIC were of equal amounts they competed equally and appeared as bands of equal intensity observed on an electrophoretic gel. Following amplification, the MIMICs for GAPDH and IL-8 produced fragments of $366 \mathrm{bp}$ and $361 \mathrm{bp}$, whereas the size of the fragments for GAPDH and IL-8 in the cDNA was $230 \mathrm{bp}$ and $216 \mathrm{bp}$, respectively.

Assessment with high-resolution computed tomography of the chest

HRCT of the chest was performed with a Toshiba TCT900S (Toshiba Medical Division, Minato-Ku, Tokyo, Japan), using a section width of $2 \mathrm{~mm}, 120-140 \mathrm{KVp}, 200 \mathrm{~mA}$ and a $1-2 \mathrm{~s}$ scan time at the end of inspiration. The images were viewed with lung windows at $700 \mathrm{HU}$ and a width of 1,200 HU. These films were reported and scored by a radiologist, as described previously $[5,15]$. Radiological severity was assessed in the following categories: 1) severity of bronchiectasis based on lumenal diameter; 2) degree of peribronchial thickening; 3) extent of bronchopulmonary segments involved by bronchiectasis; 4) number of bronchopulmonary segments involved with mucus plugging; 5) number of bronchopulmonary segments involved with sacculations; 6) generations of bronchial divisions involved with bronchiectasis or mucus plugging; 7) number of bullae; 8) emphysema; and 9) areas of collapse or consolidation. Each of these categories was given a score from $0-3$, the higher number representing more severe disease. A cumulative score was obtained from the sum of all the categories, with a maximum score of 25 and a minimum of 0 .

\section{Statistical analysis}

Statistical analysis was performed. For data that were normally distributed, a two-tailed t-test and one-way analysis of variance (ANOVA) was used. Differences in proportions between groups were analysed by the Chi-squared test. The indices of airway inflammation measured in induced sputum were not normally distributed and when reported are expressed as medians and interquartile ranges (IQR). The data were analysed after log transformation by one-way ANOVA. If the distribution was not normal despite transformation then nonparametric equivalents were used. Univariate relationships between continuous variables were examined using Spearman's rank correlation coefficient, r. Values of $\mathrm{p}<0.05$ were regarded as statistically significant. 
Table 1. - Subject characteristics

\begin{tabular}{lccc}
\hline & ABPA & Asthma & Control \\
\hline Subjects n & 29 & 9 & 21 \\
Age yrs & $56 \pm 12^{*}$ & $34 \pm 11$ & $39 \pm 9$ \\
Sex M:F & $14: 15^{*}$ & $2: 7$ & $5: 16$ \\
ICS dose & $2159 \pm 1391^{*}$ & $556 \pm 882$ & 0 \\
Lung function & & & \\
FEV1 \% pred & $56 \pm 20^{*}$ & $89 \pm 21$ & $102 \pm 11$ \\
FEV1/VC & $0.57 \pm 0.13^{*}$ & $0.76 \pm 0.12$ & $0.85 \pm 0.5$ \\
AHR \% positive & 100 & 78 & 0 \\
\hline
\end{tabular}

Data are presented as mean \pm SD. ABPA: allergic bronchopulmonary aspergillosis; M: male; F: female; ICS: inhaled corticosteroid dose, $\mu \mathrm{g} \cdot \mathrm{day}^{-1}$ beclomethasone, where $1 \mu \mathrm{g}$ beclomethasone $=1 \mu \mathrm{g}$ budesonide $=0.51 \mu \mathrm{g}$ fluticasone; FEV1: forced expiratory volume in one second; VC: vital capacity; AHR: airway hyperresponsiveness; *: $\mathrm{p}<0.05$ versus asthma, controls.

\section{Results}

The subjects with ABPA had severe asthma and airflow obstruction with an FEV1 \% pred of 56\% (table 1). Maintenance oral corticosteroids were used by $10(34 \%)$ subjects with ABPA. ABPA had intense immune activation to $A$. fumigatus (total IgE 2,009, IgGAf 57).

\section{Induced sputum}

Sputum samples were of good quality, with a median (IQR) score of 20 (15-22) out of a possible 23 and squamous contamination of $4.1 \%(1.3-12.4 \%)$. Viability was $78 \%(60-88 \%)$.

Levels of IL-8 protein in sputum supernatant were significantly higher in ABPA compared to asthma and controls $(p<0.001$, table 2, fig. 1). IL-8-positive cells were elevated in ABPA ( $\mathrm{p}=0.02$, table 2, figs. 1 and 2 ) and were predominantly neutrophils. Gene expression for IL-8 was increased in ABPA $(\mathrm{p}=0.05$, table 2$)$. There were significant associations between IL-8 levels and sputum neutrophils ( $r=0.63$, fig. 3a) and sputum macrophages $(r=-0.7)$.

Levels of sputum IL-8 protein were higher in those using regular oral corticosteroid (OCS; $53.9 \mathrm{ng} \cdot \mathrm{mL}^{-1}$ compared to $\left.4.7 \mathrm{ng} \cdot \mathrm{mL}^{-1}, \mathrm{p}=0.02\right)$, whereas IL-8 messenger (m)RNA was not different $(\mathrm{p}=0.24)$ between OCS users and nonusers. The

Table 2. - Sputum interleukin (IL)-8 protein and messenger ribonucleic acid (mRNA) levels

\begin{tabular}{lccc}
\hline & ABPA & Asthma & Control \\
\hline $\begin{array}{l}\mathrm{IL}-8 \mathrm{ng} \cdot \mathrm{mL}^{-1} \\
\begin{array}{l}\mathrm{IL}-8 \mathrm{positive} \\
\text { cells \% }\end{array}\end{array}$ & $66(23-117)^{*}$ & $\begin{array}{c}3.6(2.8-8.2) \\
2(0-23)\end{array}$ & $\begin{array}{c}3.5(2.3-4.0) \\
0(0-21)\end{array}$ \\
$\begin{array}{l}\mathrm{IL}-8 \mathrm{mRNA} \\
\mathrm{ag} \cdot \mathrm{mL}^{-1}\end{array}$ & $24(11-1750)^{*}$ & $2.4(0-108)$ & $2.4(0.02-2.4)$ \\
$\begin{array}{l}\mathrm{GAPDH} \text { mRNA } \\
\mathrm{fg} \cdot \mathrm{mL}^{-1}\end{array}$ & $2(2-24)$ & $2.4(1.1-24)$ & $2.4(1.1-10.8)$ \\
$\begin{array}{l}\mathrm{IL}-8: \mathrm{GAPDH} \\
\mathrm{ratio}\end{array}$ & $33.6(3.6-130)^{*}$ & $0.1(0-98)$ & $1.0(0.002-2.2)$ \\
\hline
\end{tabular}

Data are present as median (interquartile range). ABPA: allergic bronchopulmonary aspergillosis; GAPDH: glyceraldehyde-3phosphate dehydrogenase; ag: attogram; fg: fentograms. *: $\mathrm{p}<0.05$ versus asthma and control; ${ }^{\uparrow}: \mathrm{n}=28$, missing data due to insufficient sample.

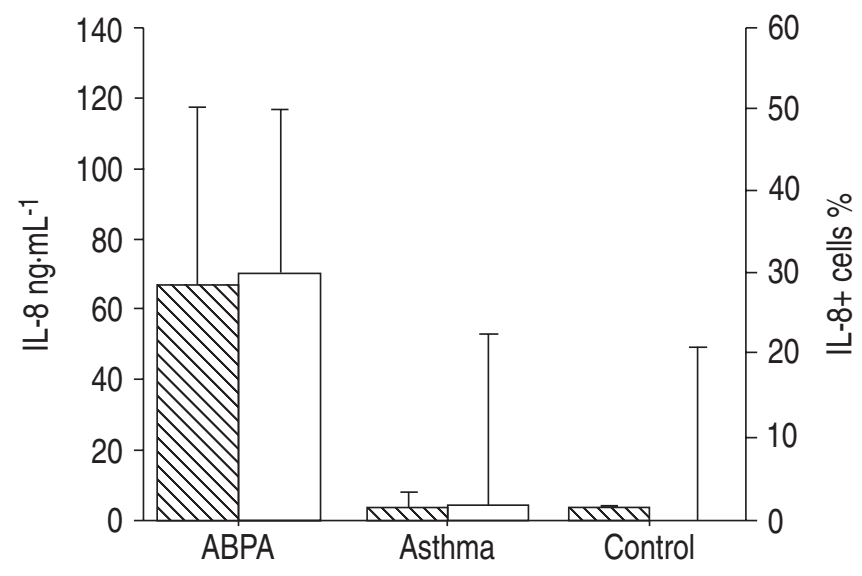

Fig. 1.-Median (interquartile range) sputum supernatant interleukin (IL)-8 (\$) and sputum cells staining positive for IL-8 ( $\square$ ) in allergic bronchopulmonary aspergillosis (ABPA), asthma and controls. $\mathrm{p}<0.05$, ABPA versus asthma, controls.

total daily dose of inhaled corticosteroid was associated with increased sputum supernatant IL-8 levels $(\mathrm{r}=0.66, \mathrm{p}<0.05)$ and IL-8-positive cells $(\mathrm{r}=0.45, \mathrm{p}<0.05)$ but not levels of mRNA for IL-8 ( $\mathrm{r}=0.16, \mathrm{p}>0.05)$.

Sputum neutrophils were significantly higher in ABPA comprising $64 \%(38-76 \%)$ of cells, compared to asthma $27 \%$ $(11-56 \%)$ and control subjects $28 \%(20-36 \%$; $\mathrm{p}=0.001$, table 3$)$. MMP-9 levels were also significantly increased in ABPA $\left(6,594 \mathrm{ng} \cdot \mathrm{mL}^{-1}\right)$, compared to asthma $\left(1,357 \mathrm{ng} \cdot \mathrm{mL}^{-1}\right)$ and controls (419 $\mathrm{ng} \cdot \mathrm{mL}^{-1}, \mathrm{p}<0.001$, table 3$)$. Increased sputum IL-8 was correlated with sputum neutrophils ( $\mathrm{r}=0.63, \mathrm{p}<0.05$, fig. 3a) and sputum MMP-9 ( $r=0.78, p<0.05$, fig. 3b), as well as $\mathrm{FEV} 1 \%$ pred $(\mathrm{r}=-0.73, \mathrm{p}<0.05$, fig. $3 \mathrm{c})$. A higher sputum IL-8 was associated with a lower FEV1.

\section{Discussion}

The pathogenesis of ABPA is typically considered to involve an IgE-mediated response to aspergillus allergens leading to tissue eosinophilia and asthma. Recently, the current authors reported an additional neutrophil airways response that correlated with the degree of lung damage on HRCT [5]. The results of the present study explore the mechanism of increased neutrophils in ABPA. The authors found that the potent neutrophil chemoattractant, IL-8, was elevated in ABPA, and therefore suggest that IL- 8 promotes neutrophil influx and activation. This in addition could lead to MMP-9 release from a variety of cells, causing subsequent lung damage. This mechanism could be activated by proteases secreted by $A$. fumigatus, since these are known to activate epithelial protease activated receptor (PAR)-2 receptors causing release of IL-8 from airway epithelium [16]. The process seems to be self-perpetuating, since sputum neutrophils were found to be positive for IL-8, suggesting autocrine IL-8 secretion may perpetuate the process [17]. This mechanism is important because it appears to be poorly responsive to corticosteroids [18].

Neutrophil-dominated airway inflammation is important in bronchiectasis from other causes [19] and is associated with release of enzymes that destroy extracellular matrix. Collagenase activity in bronchoalveolar lavage fluid is significantly elevated in postinfectious bronchiectasis and is correlated to the severity of disease. The collagenase activity appears to be predominantly due to the neutrophil-secreted MMP-8 [20]. Gelatinase activity (gelatinase B, MMP-9) is also elevated in 


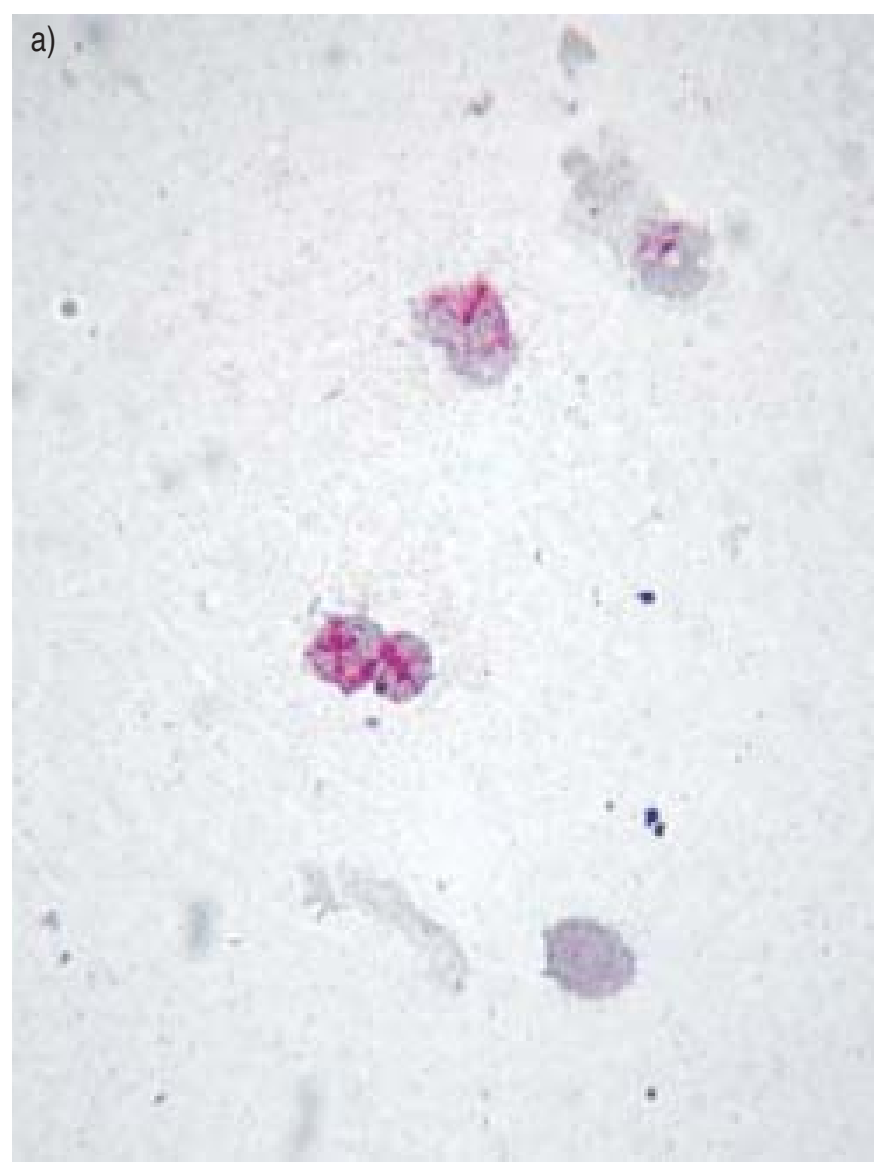

Fig. 2. - a) Interleukin-8 positive cells and b) negative controls.

bronchiectasis and correlates with disease severity [21]. MMP9 can be produced by neutrophils, monocytes, macrophages and epithelial cells, and is a marker of lung injury. In addition, there is evidence for eosinophil degranulation in bronchiectasis [22] and eosinophil granules also contain collagenases [23], including MMP-9, which is capable of degrading type IV collagen [24]. Furthermore, release of eosinophil major basic protein (MBP) can induce neutrophil degranulation and IL-8 production [25]. Thus, both eosinophils and neutrophils may play a role in promoting lung injury and leading to the degradation of extracellular matrix in ABPA.

A. fumigatus can lead to tissue damage by several different mechanisms in ABPA. There is some in-vitro evidence that $A$. fumigatus induces a mixed T-helper (Th)-1-/Th-2-type immune response [26]. In addition, A. fumigatus produces factors that impair mucociliary clearance, inhibit phagocytosis of fungal elements by neutrophils and macrophages [27], and can cause degradation of extracellar matrix proteins. A. fumigatus allergens can promote $\operatorname{IgE}$ production and eosinophilia. A. fumigatus proteases can induce epithelial IL-8 release [16], which could induce airway neutrophilia. Amplification of the response could occur with potentiating effects of eosinophil MBP on neutrophil responses [25] and autocrine IL-8 release from neutrophils [17]. The data in this study therefore support a key role for IL-8 in ABPA. There was evidence of IL- 8 protein release and increased gene expression for IL-8 in sputum cells. Confirming this, it was found that levels of IL-8 correlated with sputum neutrophils and MMP9. In addition, it was found that levels of sputum IL-8 correlated with the severity of airway obstruction in ABPA. These findings suggest that IL- 8 may be a key mediator of

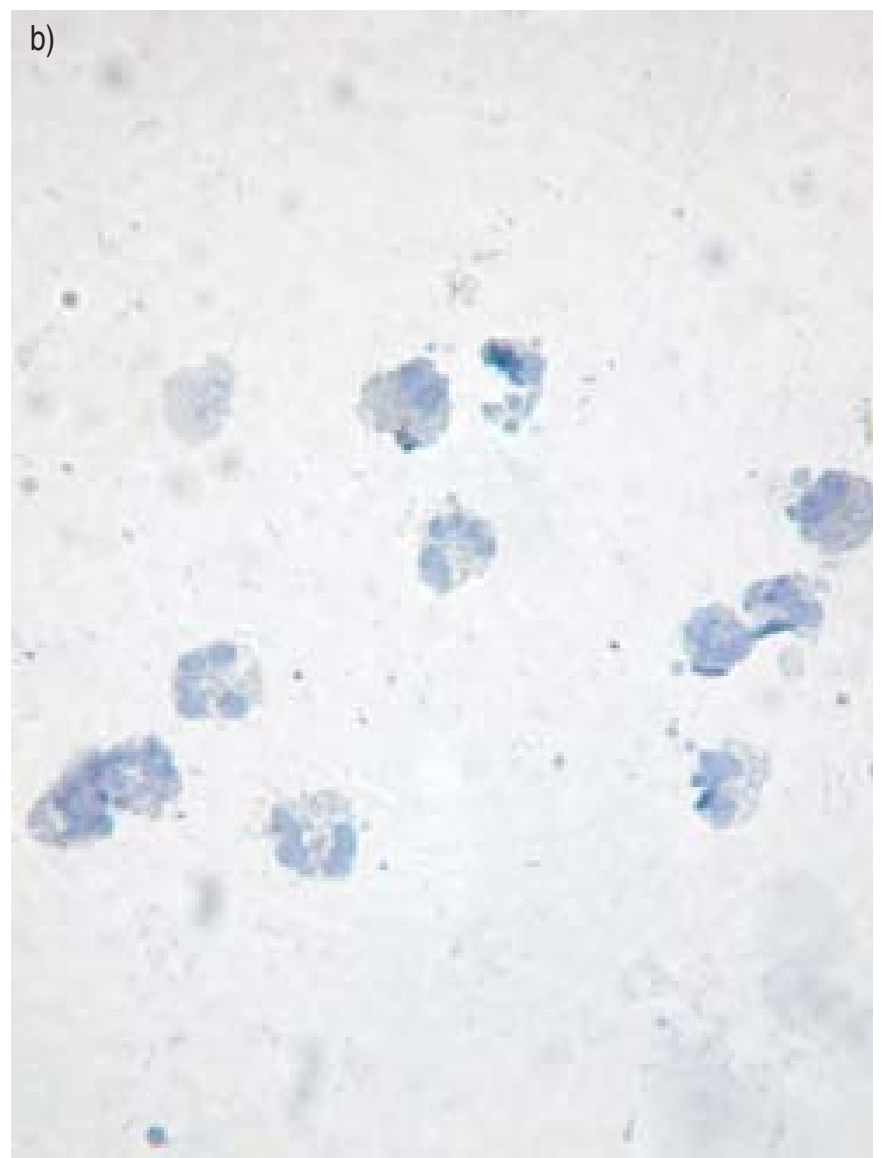

neutrophilic inflammation and a potential treatment target in ABPA.

IL-8 gene regulation requires activation of nuclear factor (NF)- $\kappa \mathrm{B}$ [28]. A. fumigatus proteases can induce IL-8 gene expression by transcription mechanisms involving enhanced DNA binding of NF- $\kappa$ B $[29,30]$. Since NF- $\kappa$ B is inhibited by inhibitory factor (IF) $-\kappa \mathrm{B}, \mathrm{NF}-\kappa \mathrm{B}$ activation may also be a target for therapy to control inflammation in ABPA. The role of corticosteroids in this process is not clear. Although corticosteroids can control the asthma in APBA, they may not prevent exacerbations or disease progression [31, 32]. The current authors found that there was evidence of active inflammation despite the use of corticosteroids [5]. This suggests that corticosteroids may not completely suppress neutrophilic inflammation in ABPA. Similar findings are reported in COPD [18] and in vitro [31]. This indicates a need for additional therapy in ABPA. Antifungal agents represent one option [32] as do treatments directed against IL-8.

MMP-9 is a marker of lung injury of many causes. It was elevated in ABPA and correlated with the severity of airflow obstruction and sputum IL-8. MMP-9 activity is inhibited by binding to tissue inhibitor of matrix metalloproteinase (TIMP)-1. The ratio of these two proteins correlates with the extent of airway disease in asthma [33]. The current authors were unable to assess TIMP-1 levels because of interference with the TIMP-1 ELISA by DTT (data not shown). The effect of DTT on the IL-8 and MMP-9 ELISAs was investigated but no interference was found.

In conclusion, this study shows that interleukin-8 protein and messenger ribonucleic acid levels are increased in allergic bronchopulmonary aspergillosis and correlate with sputum neutrophils, matrix metalloproteinase- 9 release and the severity 

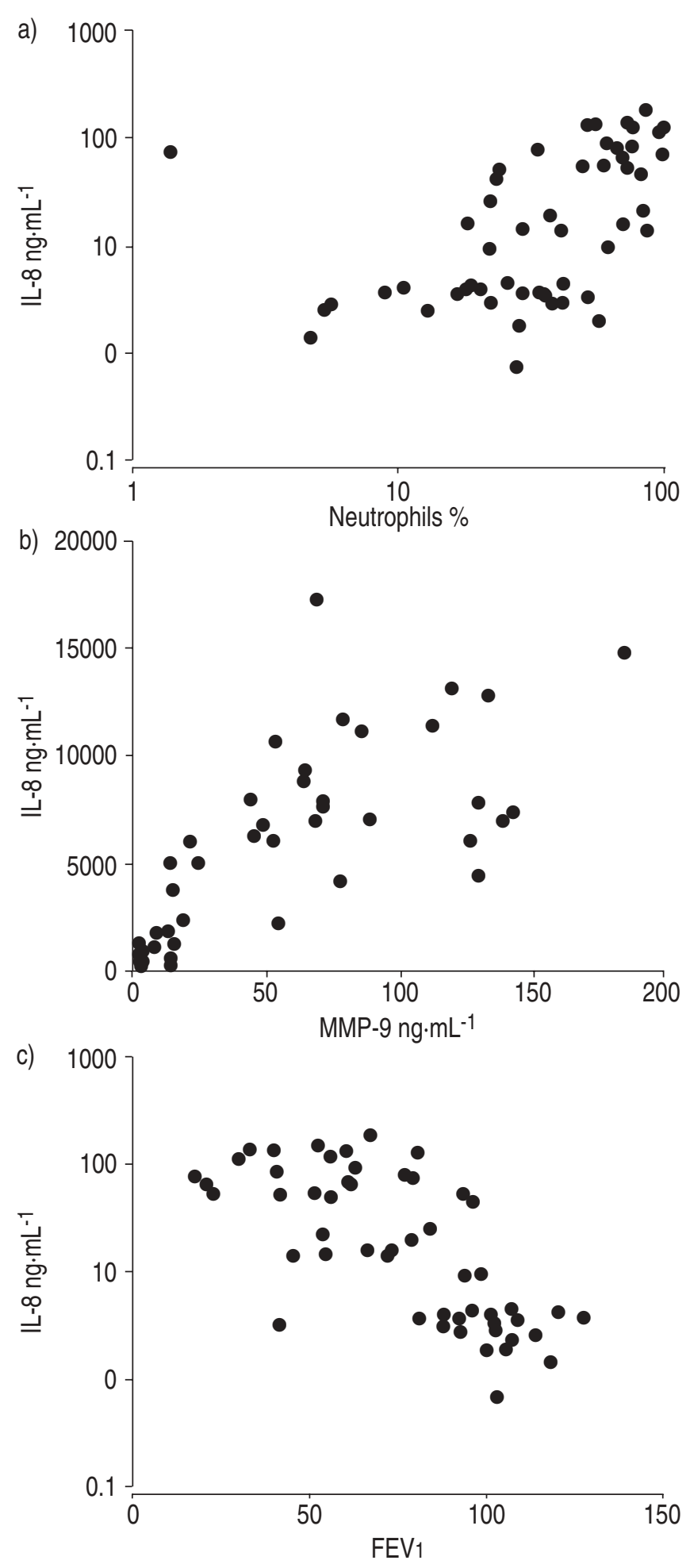

Fig. 3. - Association between a) sputum interleukin (IL)-8 and sputum neutrophils $(\mathrm{r}=0.63, \mathrm{p}<0.05), \mathrm{b})$ sputum matrix metalloproteinase (MMP)-9 ( $\mathrm{r}=0.78, \mathrm{p}<0.05)$ and $\mathrm{c})$ forced expiratory volume in one second $\left(F^{2} V_{1}\right)(r=-0.73, p<0.05)$.

of airway obstruction. Interleukin-8 may be a key mediator of inflammation and tissue damage in allergic bronchopulmonary aspergillosis and that is not completely suppressed by corticosteroid therapy. Targeting interleukin- 8 and its effects may be an important therapeutic strategy in allergic bronchopulmonary aspergillosis.
Table 3. - Sputum results

\begin{tabular}{lccc}
\hline & ABPA & Asthma & Control \\
\hline Total cell $\times 10^{6} \cdot \mathrm{mL}^{-1}$ & $7.7^{*}$ & 2.4 & 2.2 \\
Neutrophil $\%$ & $64^{*}$ & 27 & 28 \\
Eosinophil \% & $1.1^{*}$ & 0.5 & 0.0 \\
Macrophage \% & $29.7^{*}$ & 57.1 & 69.6 \\
Lymphocyte \% & 0.5 & 0.3 & 0.8 \\
Columnar epithelial \% & 1.4 & 1.8 & 2.5 \\
ECP ng. $\mathrm{mL}^{-1}$ & $6530^{*}$ & 402 & 189 \\
MMP-9 $\mathrm{ng} \cdot \mathrm{mL}^{-1}$ & $6594^{*}$ & 1357 & 419 \\
\hline
\end{tabular}

Data are presented as medians; ABPA: allergic bronchopulmonary aspergillosis; ECP: eosinophil cationic protein; MMP: matrix metalloproteinase; *: $\mathrm{p}<0.05$ versus control.

\section{References}

1. McCarthy D, Pepys J. Allergic bronchopulmonary aspergillosis. Clinical Immunology. Clinical Features. Clinical Allergy. 1971; 1: 261-267.

2. Varkey B. Allergic bronchopulmonary aspergillosis: clinical perspectives. Immunol Allergy Clin N Amer 1998; 18: 479-501.

3. Greenberger P, Miller T, Roberts M, Smith L. Allergic bronchopulmonary aspergillosis in patients with and without evidence of bronchiectasis. Ann Allergy 1993; 70: 333-338.

4. Bosken CH, Myers JL, Greenberger PA, Katzenstein AL. Pathologic features of allergic bronchopulmonary aspergillosis. Am J Surg Pathol 1988; 12: 216-222.

5. Wark PA, Saltos N, Simpson J, Slater S, Hensley MJ, Gibson PG. Induced sputum eosinophils and neutrophils and bronchiectasis severity in allergic bronchopulmonary aspergillosis. Eur Respir $J$ 2000; 16: 1095-1101.

6. Miller MD, Krangel MS. Biology and biochemistry of the chemokines: A family of chemotactic and inflammatory cytokines. Crit Review Immunol 1992; 12: 17-46.

7. Fahy JV, Kim KW, Liu J, Boushey HA. Prominent neutrophilic inflammation in sputum from subjects with asthma exacerbation. J Allergy Clin Immunol 1995; 95: 843-852.

8. Crooks SW, Bayley DL, Hill SL, Stockley RA. Bronchial inflammation in acute bacterial exacerbations of chronic bronchitis: the role of leukotriene B4. Eur Respir J 2000; 15 : 274-280.

9. Norzila MZ, Fakes K, Henry RL, Simpson J, Gibson PG. Interleukin-8 secretion and neutrophil recruitment accompanies induced sputum eosinophil activation in children with acute asthma. Am J Respir Crit Care Med 2000; 161: 769-774.

10. Pugin J, Widmer MC, Kossodo S, Liang CM, Preas HL 2nd, Suffredini AF. Human neutrophils secrete gelatinase B in vitro and in vivo in response to endotoxin and proinflammatory mediators. Am J Respir Cell Mol Biol 1999; 20: 458-464.

11. Cuzner ML, Opdenakker G. Plasminogen activators and matrix metalloproteases, mediators of extracellular proteolysis in inflammatory demyelination of the central nervous system. J Neuroimmunol 1999; 94: 1-14.

12. Smith $\mathrm{CM}$, Anderson SD. Inhalational provocation tests using non-isotonic aerosols. J Allergy Clin Immunol 1989; 84: 781-790.

13. Gibson PG, Wlodarczyk JW, Hensley MJ, et al. Epidemiological association of airway inflammation with asthma symptoms and airway hyperresponsiveness in childhood. Am J Respir Crit Care Med 1998; 158: 36-41.

14. Zhang XP, Kelemen SE, Eisen HJ. Quantitative assessment of cell adhesion molecule gene expression in endomyocardial biopsy specimens from cardiac transplant recipients using competitive polymerase chain reaction. Transplantation 2000; 70: $505-513$.

15. Bhalla M, Turcios N, Aponte N, et al. Cystic fibrosis: scoring system with thin section CT. Radiology 1991; 179: 733-738.

16. Kauffman HF, Tomee JFC, van de Reit MA, Timmerman AJB, 
Borger P. Protease-dependent activation of epithelial cells by fungal allergens leads to morphologic changes and cytokine productions. J Allergy Clin Immunol 2000; 105: 1185-1193.

17. Pang G, Ortega M, Zighang R, Reeves G, Clancy R. Autocrine modulation of IL-8 production by sputum neutrophils in chronic bronchial sepsis. Am J Respir Crit Care Med 1997; 155: 726-731.

18. Culpitt SV, Maziak W, Loukidis S, Nightingale JA, Matthews JL, Barnes PJ. Effect of high dose inhaled steroid on cells, cytokines, and proteases in induced sputum in chronic obstructive pulmonary disease. Am J Respir Crit Care Med 1999; 160: 1635-1639.

19. Cai Y, Carty K, Gibson PG, Henry RJ. Comparison of sputum processing techniques in cystic fibrosis. Pediatr Pulmonol 1996; 22: 402-407.

20. Sepper R, Konttinen YT, Ding Y, Takagi M, Sorsa T. Human neutrophil collagenase (MMP-8), identified in bronchiectasis BAL fluid, correlates with severity of disease. Chest 1995; 107: 1641-1647.

21. Sepper R, Konttinen YT, Sorsa T, Koski H. Gelatinolytic and type IV collagenolytic activity in bronchiectasis. Chest 1994; 106: 1129-1133.

22. Koller DY, Nilsson M, Enander I, Venge P, Eichler I. Serum eosinophil cationic protein, eosinophil protein $\mathrm{X}$ and eosinophil peroxidase in relation to pulmonary function in cystic fibrosis. Clin Exp Allergy 1998; 28: 241-248.

23. Davis WB, Fells GA, Sun X, Gadek JE, Venet A, Crystal RG. Eosinophil mediated injury to lung parenchymal cells and interstitial matrix. $J$ Clin Invest 1984; 74: 269-278.

24. Ohno I, Ohtani H, Nitta Y, et al. Eosinophils as a source of matrix metalloproteinase-9 in asthmatic airway inflammation. Am J Respir Cell Mol Biol 1997; 16: 212-219.
25. Kita H, Abu-Ghazaleh RI, Sur S, Gleich GJ. Eosinophil major basic protein induces degranulation and IL-8 production by human eosinophils. J Immunol 1995; 154: 4749-4758.

26. Cory DB, Grunig G, Hadeiba H, et al. Requirements for allergen induced airway hyperreactivity in $\mathrm{T}$ and $\mathrm{B}$ cell deficient mice. Mol Med 1998; 4: 344.

27. Richardson MD, Patel M. Stimulation of neutrophil phagocytosis of Aspergillus fumigatus conidia by interleukin8 and $\mathrm{N}$-formylmethionyl-leucylphenylalanine. $\mathrm{J} \mathrm{Med} \mathrm{Vet}$ Mycol 1995; 33: 99-104.

28. Kim J, Sanders SP, Siekierski ES, Casolaro V, Proud D. Role of $\mathrm{NF}-\mathrm{kB}$ in cytokine production induced from human airway epithelial cells by rhinovirus infection. J Immunol 2000; 165: 3384-3392.

29. Borger P, Koeter GH, Timmerman JA, Vellenga E, Tomee JF, Kauffman HF. Proteases from Aspergillus fumigatus induce interleukin (IL)-6 and IL-8 production in airway epithelial cell lines by transcriptional mechanisms. J Infect Dis 1999; 180: $1267-1274$

30. Tomee JF, Wierenga AT, Hiemstra PS, Kauffman HK. Proteases from Aspergillus fumigatus induce release of proinflammatory cytokines and cell detachment in airway epithelial cell lines. J Infect Dis 1977; 176: 300-303.

31. Tomee JF, van der Werf TS. Pulmonary aspergillosis. Neth $J$ Med 2001; 59: 244-258.

32. Wark PAB, Gibson PG. Allergic bronchopulmonary aspergillosis: new concepts of pathogenesis and treatment. Respirology 2001; 6: 1-7.

33. Vignola AM, Riccobono L, Mirabella A, et al. Sputum metalloproteinase-9/tissue inhibitor of metalloproteinase-1 ratio correlates with airflow obstruction in asthma and chronic bronchitis. Am J Respir Crit Care Med 1998; 158: $1945-1950$. 